\title{
Allopathy Versus Homeopathy: A Never Ending Tacit War
}

\section{Aeysha Sultan ${ }^{1 *}$, Bushra Nisar ${ }^{2}$ and Noreen Sajjad ${ }^{3}$}

${ }^{1}$ Department of Chemistry, University of Education Lahore, Okara Campus, Okara-56300, Pakistan

${ }^{2}$ Department of Chemistry, Government College Women University Faisalabad, Faisalabad-38000, Pakistan

${ }^{3}$ Department of Chemistry, University of Sargodha, Sargodha-40100, Pakistan

If we observe close enough, we would see that everything exists in pairs in nature; there is a universal antagonism whether in terms of social norms, physical phenomenon or biological processes. For every Jack there is a Jill, for every evil there is a good, for any matter there always exists an anti-matter, for every action there is a reaction and similarly for every disease there is a cure.

Many people become sick or die because of being effected by disease or diseases. But what is disease itself? Disease itself is nothing but just an atypical condition of an organism that may involve either a part or entire body of the subject. This abnormal condition renders the subject unable to carry out normal biological functions. The existence of disease is indicated in terms of signs or symptoms while the study of cause of disease is called pathology.

The medical field which claims to save the lives of suffering humanity is itself divided when it comes to the cure of disease; the difference being the basic philosophy in considering the relationship between disease and cure. These two sub-fields of medical science (better stated as medical field) are homeopathy and allopathy. Former, considered as a pseudoscience, is based on the precept "source which causes a symptom will also cure it" whilst the latter considered as a having a purely scientific basis is based on belief that the cure is something other than the cause.

The founder of homeopathy, a German physician Samuel Hahnemann (1755-1843) [1,2] believed that if a patient had an illness, it could be cured by giving a medicine which, if given to a healthy person, would produce similar symptoms of that same illness but to a slighter degree. Thus, if a patient was suffering from severe nausea, he was given a medicine which in a healthy person would provoke mild nausea. By a process he called 'proving', Hahnemann claimed to be able to compile a selection of appropriate remedies. This led to his famous maxim, 'like cures like', (aka the principle of similar).

The reason why homeopathy is considered a pseudoscience is that when put under test and the test indicates that there is no result, homeopathic practitioners don't question the premise that led to the treatment, but rather come up with anything and everything else that could be wrong. One of the core tenets of science is that when a hypothesis is disproven, it must be discarded, and experiments should seek to disprove hypotheses rather than confirm them. Allopathic medicine claims to be based on the double-blind method, and discredits any form of alternative medicine which cannot fully support every remedy or procedure with double-blind research studies. Yet allopathic medicine itself violates this principle every day. Surgeries, for example, are difficult to test by this method. When surgeries are assessed by outcomes (how many people were doing better at the end of five years, for example), millions of surgeries per year are shown to be futile or unnecessary. And sadly enough, according to allopathic research, $67 \%$ of prescriptions are made based on the side-effects of drugs-in other words, not according to the original double-blind protocol [3-8].

The allopathy, which is more recent in its origin than its counterpart, deeply believes that advances in understanding disease could only come from a detailed correlation of symptoms and signs of the sick patient on the ward, and the findings at autopsy. In allopathy, the studies and outcome of studies are purely empirical while homeopathy always involves long consultation/discussion regarding all aspects of patient's illness and life. Homeopaths consider it important to treat a subject as a whole rather curing the signs/symptoms that cause disease. Allopathic medicines attempt to alleviate the symptoms of disease by attacking/affecting the natural defense of body whereas the homeopathy embraces the body's natural response system by either encouraging the symptoms of healing or attacking the root cause of the illness.

Allopathic medicines (sometimes also referred to as orthodox medicine or conventional medicine) are considered as medicines that really work. This field of medicine is active in coping with as well challenging core concepts ingrained in minds of major population in general and physicians in particular. One such example is that of an old hypothesis that that ulcers are caused by stress that remained prevalent for decades until a doctor finally managed to persuade others that it's caused by a particular bacterial infection by infecting himself and getting ulcers.

Allopaths consider the philosophy of homeopaths to be totally baseless and claim that none, except few, cases are there whereby complete coincidence an effective treatment for diseases happens to cause symptoms similar to disease when administered to a healthy person. Homeopaths in their defense point to the fact that allopaths never understand the problems of patients but rather pick a few of symptoms call it whatever thing comes close to a textbook definition and prescribe a number of medicines meant to fight the symptoms not the problem itself. They further claim that if the allopaths are right about their belief that if the methodology of the conventional medicines is correct, or scientific in other words, then how in the world one would explain the cases when the conventional treatments don't appear to work or diseases which go away on their own without use of medications!

The debate between the effectiveness of homeopathy and allopathy, although never ending, raises many questions in favor of former and in the disfavor of latter. Most important being that if homeopathy is a non-effective pseudoscience then why is that even in this modern era of science and technology a great many number of people are favoring homeopathy $[9,10]$. Quite astonishing fact is that the number of people consulting homeopaths is increasing rapidly the most probable reason is the side effects of allopathic medicines. The number of homeopathic hospitals and clinics are opening rapidly.

People today are asking why the allopathy, although based on empirical basis, has not been able to completely cure diabetes, hepatitis, arthritis and many diseases even after advancement of science to an unfathomable level. People ask if the microbes are the only reason for

*Corresponding author: Aeysha Sultan, Department of Chemistry, University of Education Lahore, Okara Campus, Okara-56300, Pakistan, Tel: +923222520479; E-mail: Blackhawk.aries@gmail.com

Received March 24, 2016; Accepted April 14, 2016; Published April 19, 2016

Citation: Sultan A, Nisar B, Sajjad N (2016) Allopathy Versus Homeopathy: A Never Ending Tacit War. Med chem (Los Angeles) 6: 239-240. doi:10.4172/21610444.1000352

Copyright: ( 2016 Sultan A, et al. This is an open-access article distributed under the terms of the Creative Commons Attribution License, which permits unrestricted use, distribution, and reproduction in any medium, provided the original author and source are credited. 
ulcer than why antimicrobial drugs are rendered futile for its treatment. Why the microbes develop immunity against allopathic medicines only? Most importantly, if the only way to cure a disease is by fighting symptoms why the subjects suffering from tension, depression and associated diseases are cured by mediation and why is the number of deaths caused by allopathic treatments always overweighs that of homeopathy!

Although the practitioners of alternative/conventional medicines tend not to accept the label of being allopaths [11] but changing the name or considering a label pejorative does not change the scenario!

Today the allopaths (aka conventional practitioners) have to understand that symptoms in any part of body affect the body as a whole either in direct or indirect manner. The prime importance a physician must pay is to patient not symptoms. It appears that although the war between the practitioners of homeopathy and allopathy will continue but one thing for sure that homeopathy will not be the runner up!

\section{References}

1. Whorton JC (2004) The History of Alternative Medicine in America. Oxford University Press, Nature Cures.

2. Haehl R, Henry CJ (1922) Samuel Hahnemann; his life and work, based on recently discovered state papers, documents, letters, etc.

3. Lau HS, Florax C, Porsius AJ, de Boer A (2000) The completeness of medication histories in hospital medical records of patients admitted to general internal medicine wards. Br J Clin Pharmacol 49: 597-603.

4. Tam VC, Knowles SR, Cornish PL, Fine N, Marchesano R, et al. (2005) Frequency, type and clinical importance of medication history errors at admission to hospital: a systematic review. CMAJ 173: 510-515.

5. Hardmeier B, Braunschweig S, Cavallaro M, Roos M, Pauli-Magnus C, et al (2004) Adverse drug events caused by medication errors in medical inpatients. Swiss Med Weekly 134: 664-670.

6. Kanjanarat P, Winterstein AG, Johns TE, Hatton RC, Gonzalez-Rothi R, et al. (2003) Nature of preventable adverse drug events in hospitals: a literature review. Am J Health Syst Pharm 60: 1750-1759.

7. Gleason KM, Groszek JM, Sullivan C, Rooney D, Barnard C, et al. (2004) Reconciliation of discrepancies in medication histories and admission orders of newly hospitalised patients. Am J Health Syst Pharm 6: 1689-1695.

8. Cornish PL, Knowles SR, Marchesano R, Tam V, Shadowitz S, et al. (2005) Unintended medication discrepancies at the time of hospital admission. Arch Intern Med 165: 424-429.

9. Danno K, Cognet-Dementhon B, Thevenard G, Duru G, Allaert FA, et al. (2013) Effectiveness of homeopathic medicine associated with allopathic medicine in the outpatient management of influenza-like illnesses or ear, nose, and throat disorders by pharmacists. J Manag Care Pharm 19: 631-641.

10. Milgorm LR (2002) Patient-practitioner-remedy (PPR) entanglement. Part 1 a qualitative, non-local metaphor for homeopathy based on quantum theory. Homeopathy 91: 239-248.

11. Atwood KC 4th (2004) Naturopathy, pseudoscience, and medicine: myths and fallacies vs truth. MedGenMed 6: 33. 